\title{
Action of gonadotrophic hormones on cholesterol side- chain cleavage and cholesterol ester hydrolase in the ovary of the immature rat
}

\author{
H. Anne Leaver* and G. S. Boyd \\ Department of Biochemistry, University of Edinburgh, Medical School, Teviot Place, \\ Edinburgh EH8 9AG, U.K.
}

\begin{abstract}
Summary. Immature rats were injected with PMSG (Day 0) and hCG (Day 3). PMSG caused an increase in cholesterol side-chain cleavage activity and the concentration of its terminal oxidase, cytochrome P-450, and an increase in cholesterol ester hydrolase activity in ovarian homogenates; the activity of both enzymes was further increased after hCG injection. Cholesterol ester hydrolase activity $/ \mathrm{mg}$ ovarian wet weight was unchanged between Days 0 and 13, but the concentration of cytochrome P-450/mg wet weight increased 3-fold between Days 5 and 6. Cholesterol side-chain cleavage activity, measured in terms of pregnenolone production/mg wet weight, showed its largest increase (10-fold) between Days 6 and 7. Addition of exogenous cholesterol maintained the rate of pregnenolone production in incubated ovarian homogenates on Days 7-9.
\end{abstract}

\section{Introduction}

The concentrations of gonadotrophin and steroid hormone receptors change during follicular development and luteinization, and FSH and LH can bring about these changes in cultured ovarian follicles (see Channing \& Tsafriri, 1977). Alterations in receptor levels during ovarian development have been correlated with an increase in the output of oestrogen and progesterone (Richards \& Midgley, 1976). However, little is known about the activities of the enzymes involved in steroidogenesis during development and luteinization of the ovary.

In this paper, the activities of two enzymes, the cholesterol side-chain cleavage enzyme complex and cholesterol ester hydrolase, were investigated. The activity of the cholesterol side-chain cleavage enzyme is of particular interest because the rate of pregnenolone synthesis by this enzyme appears to limit the rate of steroidogenesis in ovarian follicles and corpora lutea (Dorrington, 1977). The major pool of cytochrome P-450 in the corpus luteum is mitochondrial (Stevenson \& Taylor, 1971; Arthur \& Boyd, 1974) and shows characteristics of the cytochrome P-450 that is involved in cholesterol side-chain cleavage (Jefcoate, Simpson \& Boyd, 1974). The cytochrome P-450 component of the cholesterol side-chain cleavage enzyme was measured because it takes part in the binding of cholesterol, a step thought to be regulated by $\mathrm{LH}$ (Dorrington, 1977). Cholesterol ester hydrolase activity was determined because its product, cholesterol, represents a major source of intra-ovarian steroidogenic precursor (Flint \& Armstrong, 1973).

* Present address: Department of Pharmacology, University of Edinburgh, 1 George Square, Edinburgh, EH8 9JZ, U.K. 


\section{Materials and Methods}

\section{Chemicals}

Bovine serum albumin (BSA, type F) essentially fatty acid free, isocitrate and triethanolamine hydrochloride, were purchased from the Sigma (London) Chemical Co. (Poole, Dorset, U.K.); sucrose, phosphate buffer (potassium salts), magnesium chloride, potassium chloride and sodium acetate were from BDH Ltd (Poole, Dorset, U.K.); PPO and POPOP were obtained from Koch Light Laboratories (Colnbrook, Bucks, U.K.); silica gel from E. Merk (Darmstadt, W. Germany) and PMSG (Gestyl) and hCG (Pregnyl) from Organon (Morden, U.K.). Cyanoketone ( $2 \alpha$-cyano-4,4,17 $\alpha$-trimethyl-17 $\beta$-hydroxy-5-androst-en-3-one) was a gift of Dr J. L. McCarthy (Southern Methodist University, Dallas, Texas, U.S.A.). The [4${ }^{14} \mathrm{C}$ ]cholesterol oleate (sp. act. $50 \mathrm{Ci} / \mathrm{mol}$ ) was purchased from the Radiochemical Centre (Amersham, Bucks, U.K.) and $\left[7-{ }^{3} \mathrm{H}\right]$ pregnenolone (sp. act. $17-20 \mathrm{Ci} / \mathrm{mmol}$ ) was from New England Nuclear (Hants, U.K.). All other solvents and chemicals were of the highest grade available.

\section{Animals}

Immature female Wistar rats were obtained from the Small Animal Breeding Station, University of Edinburgh. At 21-26 days of age (30-60 g) the rats were injected subcutaneously with 50 i.u. PMSG dissolved in $0.5 \mathrm{ml} \mathrm{0.9 \% (w/v)} \mathrm{NaCl}$. After 3 days the rats were given a s.c. injection of 25 i.u. hCG. Control rats were injected on Days 0 and 3 with $0.5 \mathrm{ml} 0.9 \%(\mathrm{w} / \mathrm{v})$ $\mathrm{NaCl}$. In 20-35-day-old rats plasma gonadotrophin concentrations are low (Voogt, Chen \& Meites, 1970; Goldman, Grazia, Kamberi \& Porter, 1971; Ojeda \& Ramirez, 1972). Histological examination of ovaries on Day 7 of the treatment indicated that $70 \%$ of the large follicles had ovulated forming extensively luteinized corpora lutea. The remaining $30 \%$ of the large follicles showed luteinization without ovulation.

At each day of the treatment, rats were killed by cervical dislocation and the ovaries and adrenals were placed in ice-cold $0.25 \mathrm{M}$-sucrose. Each pair of ovaries was blotted dry with filter paper before weighing, then homogenized in $3 \mathrm{ml} 0.25 \mathrm{M}$-sucrose. Determinations of cholesterol side-chain cleavage activity and cytochrome P-450 content were performed within $2 \mathrm{~h}$ of death. The cholesterol side-chain cleavage multi-enzyme complex is located in the mitochondria of the corpus luteum (Yago, Dorfman \& Forchielli, 1967; Sulimovici \& Boyd, 1968) but determinations were carried out on the homogenate for two reasons; firstly, cholesterol side-chain cleavage activity deteriorates within $2-3 \mathrm{~h}$ of death, and secondly, during subcellular fractionation procedures there is a loss of $\sim 50 \%$ of enzyme activity from 'mitochondrial' fractions (Leaver, 1978). Each determination of ovarian or adrenal weight, cytochrome P-450 content and cholesterol side-chain cleavage activity was carried out on duplicate incubations from 3 groups of rats. Each group contained 4 rats. Control values were obtained from duplicate incubations from one group of 4 rats.

\section{Cholesterol side-chain cleavage enzyme}

Cholesterol side-chain cleavage was assayed after initiation of the reaction by addition of the electron donor isocitrate $(10 \mathrm{~mm})$. Cyanoketone was included in all assays to inhibit the metabolism of pregnenolone by the $3 \beta$-hydroxysteroid dehydrogenase. Incubations were carried out in the following buffer ( $\mathrm{pH} 7.0$ ): sucrose, $250 \mathrm{~mm}$; potassium chloride, 20 mm; triethanolamine hydrochloride, $15 \mathrm{~mm}$; potassium phosphate, $10 \mathrm{~mm}$; magnesium chloride, 5 mM; ethylenediaminetetracetic acid, $0.2 \mathrm{~mm}$; bovine serum albumin (defatted), $0.1 \%$; cyanoketone, $6.0 \mu \mathrm{M}$. Ovarian homogenate $(0.1 \mathrm{ml})$ and buffer $(1.7 \mathrm{ml})$ were incubated in glass centrifuge tubes. Aliquots $(0.5 \mathrm{ml})$ of the reaction mixture were transferred to $4 \mathrm{ml}$ methanol to 
terminate the reaction after the addition of isocitrate (zero time). Chloroform $(5 \mathrm{ml})$ and water (2 $\mathrm{ml}$ ) were added to the extract and the organic layer was assayed for pregnenolone; $\left[{ }^{3} \mathrm{H}\right]$ pregnenolone was used as a recovery marker (Mason, Arthur \& Boyd, 1978). Recovery was $92 \pm 4 \%$ and results were corrected to $100 \%$ recovery. The pregnenolone radioimmunoassay, using antisera raised in New Zealand White rabbits to pregnenolone-20-bovine serum albumin complex, was a modification (Mason et al., 1978) of the method of Abraham, Buster, Kyle, Corvales \& Teller (1973). The intra- and inter-assay coefficients of variation were 4 and $8 \%$ respectively. The sensitivity of the assay was $200-3000 \mathrm{pg}$ pregnenolone, and the crossreactivity of the antiserum was $0.72 \%$ with progesterone, $1.33 \%$ with pregn-5-en-3 3 -ol, and $<0.1 \%$ with $\mathrm{S}$ cholen-3 $\beta$-ol, cholesterol and cyanoketone. Cytochrome P-450 was determined using an Aminco split-beam, dual-wavelength spectrophotometer (Estabrook, Peterson, Baron \& Hildebrandt, 1972), using an extinction coefficient of $91 \mathrm{~mm}^{-1} \cdot \mathrm{cm}^{-1}$ for the absorbance change at $450-190 \mathrm{~nm}$. The reducing agent was sodium dithionite.

\section{Cholesterol ester hydrolase}

The buffer was the same as that used for the assay of cholesterol side-chain cleavage activity (pH 7). Protein concentration was $0.1-0.2 \mathrm{mg} / \mathrm{ml}$ and the incubation volume was $4.6 \mathrm{ml}$. Cholesterol ester hydrolase activity was initiated by addition of $60 \mathrm{nmol}(1.89 \mu \mathrm{Ci})$ [4- ${ }^{14} \mathrm{C}$ ]cholesterol oleate in $20 \mu \mathrm{l}$ acetone. The incubation mixture was placed immediately into a shaking water bath at $37^{\circ} \mathrm{C}$ and endogenous cholesterol ester was determined on Days 12 and 13 when cholesterol ester concentration was highest (Guraya, 1975; Strauss, Seiffer, Lieu, Goodman \& Stambaugh, 1977; Schuler, Scavo, Kirsch, Flickinger \& Strauss, 1979). A BDH Clinical Assay Set for the determination of cholesterol and cholesterol ester was used. Endogenous cholesterol ester ( $\sim 25 \mathrm{nmol} / \mathrm{mg}$ protein) never represented more than $20 \%$ of added cholesterol ester. The reaction was terminated after $60 \mathrm{~min}$ by addition of $10 \mathrm{ml}$ methanol. The rate of cholesterol ester hydrolase activity over this period was linear.

Sterols were partitioned into $10 \mathrm{ml}$ chloroform by using the chloroform : methanol extraction procedure of the cholesterol side-chain cleavage assay (Mason et al., 1978). Extracted cholesterol and cholesterol esters were separated by chromatography on thin-layer plates coated with silica gel $\mathrm{H}$; the solvent system was diisopropyl ether:petroleum ether $\left(60-80^{\circ} \mathrm{C}\right.$ b.p.): glacial acetic acid (70:30:2 by vol.). Two radioactive peaks were obtained and were identified as cholesterol and cholesterol oleate from standards run at the side of the plate. The areas corresponding to these two peaks were scraped from the t.l.c. plate into scintillation vials and radioactivity was counted after the addition of scintillator. The recovery of ${ }^{14} \mathrm{C}$ from incubations after extraction and thin-layer chromatography varied between 83 and $97 \%$. The recovery of $\left[{ }^{14} \mathrm{C}\right]$ cholesterol was not significantly different $(P>0.05)$ from the recovery of $\left[{ }^{14} \mathrm{C}\right]$ cholesterol oleate. Cholesterol ester hydrolase activity was expressed in terms of the metabolism of exogenous ester. The limit of detection of this method was $1 \mathrm{nmol}$ cholesterol per incubation, and intra- and inter-assay coefficients of variation were 7 and $9 \%$, respectively.

\section{Statistical analysis of data}

Results, expressed as mean \pm s.e.m., were analysed by Student's $t$ test, and were deemed significant when $P<0.05$.

\section{Results}

Ovarian and adrenal cytochrome P-450

The cytochrome P-450 content of ovarian homogenate and the wet weight of the ovary were increased by gonadotrophin treatment (Table 1). The cytochrome P-450 content of the tissue 
increased after the PMSG injection. The ovulatory hCG injection was followed by a 3 -fold rise in ovarian cytochrome P-450 content between Days 5 and 6 although the ovarian weight increase at this time was not significant. Cytochrome P-450 concentration was therefore increased (Text-fig. 1) to a greater extent than would be expected as a result of generalized tissue growth. Adrenal cytochrome P-450 concentration decreased from $110 \pm 42$ to $43 \pm 32$ $\mu \mathrm{mol} / \mathrm{mg}$ weight between Days 0 and 13.

Table 1. Enzyme activities (mean \pm s.e.m. of 6 determinations) in the ovaries of rats treated with PMSG (Day 0) and hCG (Day 3) or saline only (values in parentheses)

\begin{tabular}{|c|c|c|c|c|c|c|}
\hline \multirow{2}{*}{$\begin{array}{l}\text { Day of } \\
\text { treat- } \\
\text { ment }\end{array}$} & \multirow{2}{*}{$\begin{array}{l}\text { Wet wt } \\
\text { (mg) }\end{array}$} & \multirow{2}{*}{$\begin{array}{c}\text { Cytochrome } \\
\text { P-450 } \\
\text { (nmol/2 } \\
\text { ovaries) }\end{array}$} & \multirow{2}{*}{$\begin{array}{c}\text { Pregnenolone } \\
\text { content } \\
\text { (nmol } / 2 \\
\text { ovaries) }\end{array}$} & \multicolumn{2}{|c|}{$\begin{array}{l}\text { Pregnenolone synthesis } \\
\text { (nmol } / 2 \text { ovaries } / \mathrm{min} \text { ) }\end{array}$} & \multirow{2}{*}{$\begin{array}{l}\mathrm{CEH}^{*}(\mathrm{nmo} \\
\text { cholesterol/2 } \\
\text { ovaries } / \mathrm{min} \text { ) }\end{array}$} \\
\hline & & & & $0-1.5 \mathrm{~min}$ & $0-9 \mathrm{~min}$ & \\
\hline 0 & 10 & 0.008 & $1.3 \pm 0.2$ & $0.13 \pm 0.01$ & $0.09 \pm 0.01$ & $\begin{array}{c}0.25 \pm 0.12 \\
(0.20)\end{array}$ \\
\hline 1 & $15 \pm 5$ & 0.04 & $2.9 \pm 0.2$ & $<0.05$ & $0.17 \pm 0.11$ & $0.33 \pm 0.09$ \\
\hline 2 & $100 \pm 20$ & $\begin{array}{c}0.32 \pm 0.05 \\
(0.06)\end{array}$ & $3.5 \pm 0.4$ & $1.7 \pm 0.20$ & $1.10 \pm 0.21$ & $\begin{array}{c}0.20 \pm 0.09 \\
(0.15)\end{array}$ \\
\hline 3 & $145 \pm 5$ & $0.28 \pm 0.03$ & - & - & - & $1.1 \pm 0.02$ \\
\hline 4 & $210 \pm 20$ & $\begin{array}{c}0.47 \pm 0.02 \\
(0.08)\end{array}$ & - & - & - & $\begin{array}{c}2 \cdot 15 \pm 0.25 \\
(0.25)\end{array}$ \\
\hline 5 & $275 \pm 15$ & $0.60 \pm 0.30$ & $28.4 \pm 3.0$ & $3.0 \pm 0.3$ & $3 \cdot 3 \pm 1 \cdot 1$ & $2.95 \pm 0.15$ \\
\hline 6 & $290 \pm 30$ & $\begin{array}{c}1.94 \pm 0.50 \\
(0.02)\end{array}$ & $62 \cdot 3 \pm 8 \cdot 1$ & $0.9 \pm 0.5$ & $2.8 \pm 0.6$ & $\begin{array}{c}5.00 \pm 0.10 \\
(0.20)\end{array}$ \\
\hline 7 & $330 \pm 60$ & $1.70 \pm 0.70$ & $40.4 \pm 2.4$ & $23.4 \pm 9.1$ & $14.8 \pm 4.3$ & $2.75 \pm 0.80$ \\
\hline 8 & $\begin{array}{c}310 \pm 30 \\
(35)\end{array}$ & $\begin{array}{c}1.65 \pm 0.47 \\
(0.07)\end{array}$ & $50 \cdot 5 \pm 8 \cdot 6$ & $33 \cdot 1 \pm 9 \cdot 0$ & $16 \cdot 5 \pm 5 \cdot 1$ & $\begin{array}{c}2.95 \pm 0.55 \\
(0.25)\end{array}$ \\
\hline 9 & $275 \pm 30$ & $2 \cdot 13 \pm 0.50$ & $50.7 \pm 17.6$ & $8.5 \pm 3.7$ & $4 \cdot 1 \pm 1.9$ & $4 \cdot 10 \pm 0 \cdot 50$ \\
\hline 10 & $\begin{array}{c}300 \pm 45 \\
(40)\end{array}$ & $\begin{array}{c}1.95 \pm 0.43 \\
(0.07)\end{array}$ & $36 \cdot 3 \pm 8 \cdot 0$ & $1.5 \pm 0.5$ & $0.8 \pm 0.2$ & $\begin{array}{c}2.25 \pm 0.13 \\
(0.20)\end{array}$ \\
\hline 11 & $190 \pm 40$ & $1.24 \pm 0 \cdot 14$ & $27 \cdot 5 \pm 9 \cdot 0$ & $2 \cdot 7 \pm 1.2$ & $2.5 \pm 0.6$ & $2.65 \pm 0.15$ \\
\hline 12 & $\begin{array}{c}210 \pm 10 \\
(40)\end{array}$ & $\begin{array}{c}1 \cdot 10 \pm 0.34 \\
(0.08)\end{array}$ & - & - & - & $\overline{(0.40)}$ \\
\hline 13 & $235 \pm 25$ & $1.28 \pm 0.11$ & - & $2.8 \pm 0.8$ & $1.6 \pm 0.9$ & - \\
\hline
\end{tabular}

* Cholesterol ester hydrolase was measured over $60 \mathrm{~min}$.

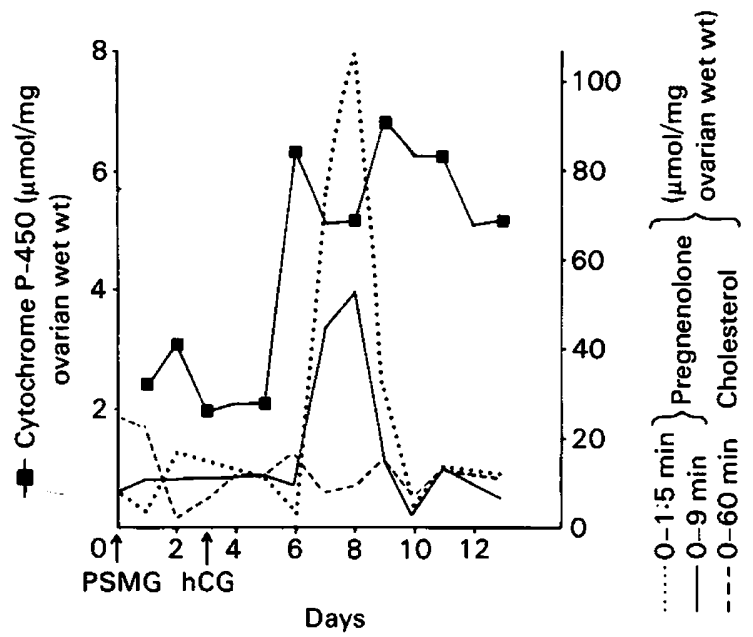

Text-fig. 1. The effect of PMSG and hCG treatment on cytochrome P-450, pregnenolone production, and cholesterol ester hydrolase activity in rat luteal tissue. Results are the mean of 6 determinations, divided by the mean ovarian weight, on each day of the treatment (see Table 1). 


\section{Ovarian cholesterol side-chain cleavage}

The ovarian content of pregnenolone, determined in homogenates before incubation, increased after PMSG and hCG treatment (Table 1). The rate of cholesterol side-chain cleavage in the homogenate continued to increase over a 9-min incubation period when the tissue was taken on Days 0-6 and 10-13 (Table 1). However, on Days 7-9 cholesterol side-chain cleavage activity declined during incubation. This decline was prevented by the addition of cholesterol in $10 \mu \mathrm{l}$ acetone to a final concentration of $86 \mu \mathrm{M}$, which represents approximately 3 times the concentration of endogenous unesterified cholesterol present in the homogenate $(\sim 33 \mu \mathrm{M})$ (Text-fig. 2). Addition of exogenous cholesterol did not increase the rate of pregnenolone synthesis in homogenates of ovaries taken at Days 5-6 and 10-11. The initial $(0-1.5 \mathrm{~min})$ rate of cholesterol side-chain cleavage activity increased significantly after the hCG injection and by 4 days after hCG (i.e. Day 4) had increased to a greater extent than had cytochrome P-450 content (Text-fig. 1). Cytochrome P-450 concentrations increased 2 days after hCG injection, in the absence of a corresponding increase in cholesterol side-chain cleavage activity.

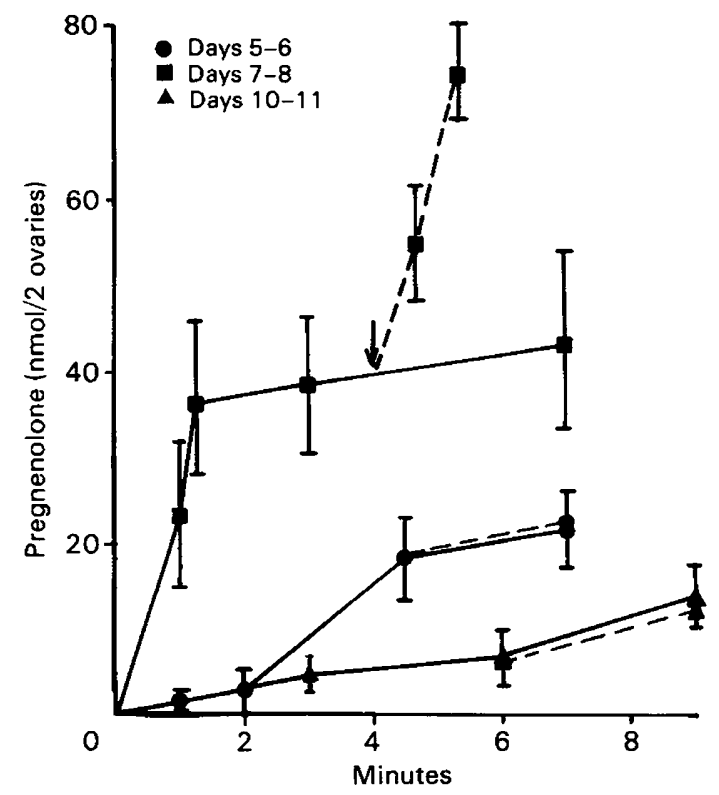

Text-fig. 2. The production of pregnenolone by ovarian homogenates of rats treated with PMSG (Day 0) and hCG (Day 3). Results are the mean \pm s.e.m. of 6 determinations carried out on duplicate incubations. Values obtained after addition of $86 \mu \mathrm{M}$-cholesterol are also shown $(----)$.

Table 2. Activity (mean \pm s.e.m. of 4 determinations) of cholesterol ester hydrolase in the ovaries of rats treated with PMSG (Day 0) and hCG (Day 3)

\begin{tabular}{ccc}
\hline & \multicolumn{2}{c}{$\begin{array}{c}\text { Cholesterol ester hydrolase activity* } \\
\text { (nmol cholesterol/2 ovaries/min) }\end{array}$} \\
\cline { 2 - 3 } $\begin{array}{c}\text { Day of } \\
\text { treatment }\end{array}$ & $94000 \mathrm{~g}$ pellet & $94000 \mathrm{~g}$ supernatant \\
\hline 2 & $0.42 \pm 0.07$ & $0.19 \pm 0.03$ \\
7 & $0.45 \pm 0.02$ & $0.40 \pm 0.06$ \\
9 & $1.17 \pm 0.08$ & $1.12 \pm 0.06$ \\
\hline
\end{tabular}

* Cholesterol production from exogenous $\left[1-{ }^{14} \mathrm{C}\right]$ cholesterol oleate in duplicate incubations. 


\section{Ovarian cholesterol ester hydrolase}

Gonadotrophin treatment increased ovarian cholesterol ester hydrolase activity (Table 1). Activity in the particulate and supernatant fractions was increased (Table 2). The increased activity closely paralleled the increase of ovarian weight (Text-fig. 1).

\section{Discussion}

The aim of this study was to investigate the effect of gonadotrophins on the development of cholesterol side-chain cleavage and cholesterol ester hydrolase, and the relation of this development to the steroidogenic output of the ovary.

The gonadotrophins PMSG and hCG were used to induce ovarian development in immature animals. The ultrastructural changes induced by PMSG and by hCG resemble changes occurring in granulosa cells during luteinization (Bramley, Ryan, Kang, Perotti \& Anderson, 1980), and PMSG and hCG have been shown to increase oestrogen and progesterone output, respectively, from the immature rat ovary (Wilson, Horth, Endersby \& McDonald, 1974; Parker, Costoff, Moldoon \& Mahesh, 1976; Shashida \& Johnson, 1976; Tan \& Robinson, 1976, 1977). The corpus luteum of PMSG-hCG-treated rats resembles the corpus luteum of pregnancy in its steroidogenic output and the modulation of this output by LH. However, the pattern of follicular growth in these rats differs from that of the adult cyclic rat in that ovarian elements from previous ovulations, which could contribute to steroidogenesis, are not present (Cortes, McCracken, Lloyd \& Weisz, 1971). We were therefore monitoring the primary response of undifferentiated ovarian elements to gonadotrophins. High doses of gonadotrophins, such as those used in the present study, may induce some follicular luteinization without ovulation and these PMSG-hCG-treated rats do not exhibit the decidualization response (Guillet \& Rennels, 1964).

Our data show an increase in cholesterol side-chain cleavage activity in response to PMSG and hCG injections. The peak in cholesterol side-chain cleavage activity on Days 7, 8 and 9 of the treatment procedure corresponded with the period of highest concentrations of peripheral plasma progesterone in Sprague-Dawley rats (Tan \& Robinson, 1977). However, the increase in cholesterol side-chain cleavage activity between Days 6 and 7 was an order of magnitude greater than the rise in plasma progesterone, suggesting that some factor other than cholesterol side-chain cleavage activity may limit the rate of steroidogenesis over this period.

One factor which appeared to limit the output of pregnenolone from the ovary on Days 7-9 was the supply of unesterified cholesterol. A decrease in pregnenolone production during incubation was observed on Days 7 and 8 and addition of exogenous unesterified cholesterol restored pregnenolone synthesis to the original value.

Cholesterol ester hydrolase activity, which represents a source of intra-ovarian unesterified cholesterol for steroidogenesis, was increased by PMSG and hCG injections. The activities of cytosolic and particulate enzymes (at pH 7.0) were stimulated. However, between Days 5 and 8 when cholesterol side-chain cleavage activity increased 10 -fold, there was no significant increase in cholesterol ester hydrolase activity. The supply of cholesterol via cholesterol ester hydrolase did not, therefore, appear to keep pace with an increased demand for steroidogenic precursor at this time. This suggests that the concentration of plasma cholesterol could play an important part in progesterone output by the corpus luteum.

The adrenal decline in cytochrome may be due to a decrease in the level of circulating ACTH in the PMSG-hCG-pretreated rat, because it resembles the fall in adrenal cytochrome P-450 levels reported after hypophysectomy (Purvis, Canick, Mason, Estabrook \& McCarthy, 1973). Whatever the mechanism, however, the influence of gonadotrophins on adrenal cytochrome P-450 suggests an overlap between gonadal and adrenocortical feedback. 
Ovarian cytochrome P-450 increased after PMSG and hCG injections. A rapid increase in cytochrome P-450 was observed on Days 5-6, preceding the increase in cholesterol side-chain cleavage activity on Days 7, 8 and 9 . This indicates that an increase in ovarian cytochrome P-450 is an important prerequisite in the development of steroidogenesis. However, during the period of increase in cholesterol side-chain cleavage activity (Days 6-7), ovarian total cytochrome P-450 levels did not change significantly. Cytochrome P-450 concentration is therefore not the only factor which limits the development of ovarian cholesterol side-chain cleavage activity. It is possible that the rate-limiting factor appearing between Days 6 and 7 is similar to the mitochondrial 'factor' important in the acute response of the developed corpus luteum to LH (Dorrington, 1977).

This work was supported by an M.R.C. programme grant, and H.A.L. was the recipient of an Edinburgh Medical Faculty Grant. We are grateful for the advice of Dr J. I. Mason (Worcester Foundation, Massachusetts) and Dr T. A. Bramley (Obstetrics and Gynaecology, University of Edinburgh) in preparing this manuscript.

\section{References}

Abraham, G.E., Buster, J.E., Kyle, F.W., Corvales, P.G. \& Teller, R.C. (1973) Radioimmunoassay of plasma pregnenolone. J. clin. Endocr. Metab. 37, 40-45.

Arthur, J.R. \& Boyd, G.S. (1974) The effect of inhibitors of protein synthesis on cholesterol side-chain cleavage in the mitochondria of luteinized rat ovaries. Eur.J. Biochem. 49, 117-127.

Bramley, T.A., Ryan, R.J., Kang, Y.H., Perotti, M.E. \& Anderson, W. (1980) Interactions of gonadotrophins with corpus luteum membranes. X. Biochemical and morphological changes in surface-membranes during PMSG/HCG induced luteinization of the rat ovary. Molec. cell. Endocr. 19, 43-56.

Channing, C.P. \& Tsafriri, A. (1977) Mechanism of action of luteinising hormone and follicle-stimulating hormone on the ovary in vitro. Metabolism 26, 413-468.

Cortes, V., McCracken, J.A., Lloyd, C.W. \& Weisz, J. (1971) Progestin production by the ovary of the testosterone-sterilized rat treated with an ovulatory dose of LH, and the normal, proestrous rat. Endocrinology 89, 878-885.

Dorrington, J.H. (1977) Steroidogenesis in vitro. In The Ovary, 2nd edn, Vol. III, pp. 359-412. Eds S. Zuckerman \& B. J. Weir. Academic Press, New York.

Estabrook, R.W., Peterson, J., Baron, J. \& Hildebrandt, A. (1972) The spectrophotometric measurement of turbid suspensions of cytochromes associated with drug metabolism. In Methods in Pharmacology, Vol. 2, pp. 303-350. Ed. C. F. Chignell. AppletonCentury-Croft, New York.

Flint, A.P.F. \& Armstrong, D.T. (1973) Activities of enzymes responsible for steroid biosynthesis and cholesterol ester metabolism in rabbit ovarian interstitial tissue and corpora lutea. Biochem. J. 132, 301-311.

Goldman, B.D., Grazia, Y.R., Kamberi, I.A. \& Porter, J.C. (1971) Serum gonadotrophin concentration in intact and castrated neonatal rats. Endocrinology 88, 771-776.

Guillet, G.G. \& Rennels, E.G. (1964) The experimental production of deciduomata in immature rats. Tex. Rep. Biol. Med. 22, 78-93.

Guraya, S.S. (1975) Histochemical observations on the lipid changes in the rat corpus luteum during various reproductive states. $J$. Reprod. Fert. 42, 59-65.

Jefcoate, C.R., Simpson, E.R. \& Boyd, G.S. (1974) Spectral properties of rat adrenal-mitochondrial cytochrome P-450. Eur. J. Biochem. 42, 539-551.

Leaver, H.A. (1978) Steroidogenesis and its control in rat corpus luteum. Ph.D. thesis, University of Edinburgh.

Mason, J.I., Arthur, J.R. \& Boyd, G.S. (1978) Regulation of cholesterol metabolism in rat adrenal mitochondria. Molec. cell. Endocr. 10, 209-223.

Ojeda, S.R. \& Ramirez, V.D. (1972) Plasma level of LH and $\mathrm{FSH}$ in maturing rats: response to hemigonadectomy. Endocrinology 90, 466-472.

Parker, C.R., Jr, Costoff, A., Moldoon, T.G. \& Mahesh, V.B. (1976) Actions of pregnant mare serum gonadotrophin in the immature female rat: correlative changes in blood steroids, gonadotrophin receptors, and cytoplasmic estradiol receptors of the anterior pituitary and hypothalamus. Endocrinology 98, 129-138.

Purvis, J.L., Canick, J.A., Mason, J.I., Estabrook, R.W. \& McCarthy, J.L. (1973) Lifetime of adrenal cytochrome P-450 as influenced by ACTH. Ann. N.Y. Acad. Sci. 212, 319-343.

Richards, J.S. \& Midgley, J.R. (1976) Protein hormone action: a key to understanding ovarian follicular and luteal cell development. Biol. Reprod. 14, 82-94.

Schuler, L.A., Scavo, L., Kirsch, T.M., Flickinger, G.L. \& Strauss, J.F. (1979) Regulation of de novo biosynthesis of cholesterol and progestins, and formation of cholesteryl ester in rat corpus luteum by exogenous sterol. J. biol. Chem. 254, 8662-8668.

Shashida, T. \& Johnson, D.C. (1976) The response of the immature rat ovary to gonadotrophins: acute changes in cyclic AMP, progesterone, testosterone, androstenedione and oestradiol after treatment with PMS or FSH + LH. Acta endocr., Copenh. 82, 413-425. 
Stevenson, P.M. \& Taylor, P.L. (1971) 'Malic enzyme' and alkaline phosphatase in mitochondria from pig and rat ovaries. FEBS Letters 19, 251-254.

Strauss, J.F., Seiffer, R., Lieu, E.L., Goodman, D.B.P. \& Stambaugh, R.L. (1977) Lipid metabolism in the regressing rat corpora lutea of pregnancy. J. Lipid Res. 18, 246-258.

Sulimovici, S. \& Boyd, G.S. (1968) The cholesterol side-chain cleavage enzymes in the immature rat ovary. Eur. J. Biochem. 3, 332-345.

Tan, C.H. \& Robinson, J. (1976) The use of the superovulated rat in studies on the acute steroidogenic effect of luteinising hormone. J. Endocr. $69,38 P$.

Tan, C.H. \& Robinson, J. (1977) The superovulated rat: its use as a model in studies on the acute steroidogenic effects of luteinising hormone. Endocrinology 101, 396-402.

Voogt, J.L., Chen, C.L. \& Meites, J. (1970) Serum and pituitary prolactin levels before, during and after puberty in female rats. Am. J. Physiol. 218, 396-399.

Wilson, C.A., Horth, C.E., Endersby, C.A. \& McDonald, P.S. (1974) Changes in plasma levels of oestradiol, progesterone and luteinising hormone in immature rats treated with pregnant mare serum gonadotrophin. J. Endocr. 60, 293-304.

Yago, N., Dorfman, R.I. \& Forchielli, E. (1967) Extra-mitochondrial NADPH and cholesterol sidechain cleaving enzyme system in the heavy mitochondria of bovine corpora lutea. J. Biochem. (Tokyo) 62, 345-352.

Received 17 October 1980 